\title{
Numerical Approach for the Live Load Distribution in Road Bridges
}

\author{
Janusz Hołowaty \\ Faculty of Civil Engineering and Architecture, West Pomeranian University of Technology, Szczecin 70-311, Poland
}

\begin{abstract}
The numerical method for computing the live load distribution coefficients in bridge decks is presented. The grillage analogy for representation of bridge decks is adopted in determining the general behavior under traffic loads. The principles of Maxwell's reciprocal theorem are developed in computing live load distribution coefficients and their influence lines. The presented method uses the approach developed in traditional methods of transversal live load distribution but bridge decks are modeled more realistic with the help of well-established grillage analogy. Simple numerical programs for grillage analysis can be used and no special software is needed. While computing the distribution coefficients for a bridge deck the rest of the analysis can be performed with habitual procedures of structural mechanics.
\end{abstract}

Key words: Numerical model, bridge live load, numerical modeling, grillage method, FE analysis.

\section{Introduction}

In the design or assessment of bridges many numerical or empirical methods are employed. Usually the capacity procedures for designing or checking bridge structures are codified in every country. Some codes use simplified but generally very safe procedures, other codes require detailed and sophisticated analysis. In the decade of numerical method the influence lanes for internal forces or live load distribution are still very popular among bridge engineers because they give visual picture of critical regions at glance. The distribution coefficients or their influence lines are used for calculation of live loads for a particular bridge girder or beam.

The first modern distribution coefficient method was introduced by Guyon and Massonnet in the end of 1940's and the method had been introduced to many countries since then [1]. Development of the methods resulted in codifying them in North America for designing and assessment in AASHTO and Ontario codes.

Corresponding author: Janusz Hołowaty, Ph.D., assistant professor, research field: testing and design of bridges. E-mail: jah@wp.pl.
Nowadays the availability of wide range of computer programs for structural analysis and a computer at every desk enables the analysis of bridge decks to be done with high accuracy and efficiency. The old ideas of transverse load distribution for bridge girders can be solved with the help of even small personal computer. However the traditional methods of transversal load distribution are seemed a little out of fashion and sometimes too crude.

In the paper a numerical method of computing transverse distribution of load in bridge decks is presented. The grillage analogy is applied for modelling different types of bridge decks as a well establish and refined technique [2, 3-11]. While computing load distribution coefficients by the grillage the remaining analysis can be done with line beam analysis. Examples of computed load distribution coefficients which were used for existing bridge decks are presented and compared with simplistic rules.

\section{Load Distribution-Background}

In road bridges it is necessary to consider the action of moving loads like wheel or axle loads, and trucks 
or special vehicles. Sometimes bridges are also checked for military loads. For designing, the models for traffic loading are embodied in codes. For assessment, it is often necessary to consider a real truck or exceptional loads. Members of a bridge must be design or checked for the most severe state that can be introduced in the member by moving loads. The crucial position of traffic loads is not the same for all members.

The oldest and the most useful methods of analyzing the most extreme position of loading are influence lines. As for bending moments and shear, influence lines can be also used for a wheel load distribution. To simplify the process of analyzing bridge decks the load distribution coefficients were introduced. The use of influence lines for transverse load distribution simplified the analysis of bridge girders to line beam analysis (1D).

In the early methods, wheel loads were distributed to each member using simple static, next classical plate theory was used. To solve the problem some assumptions were developed. Instead of an original bridge deck system for the purpose of analysis, an equivalent orthotropic plate was investigated. In the more refined methods the flexure and torsion rigidities were determined in such a manner that the properties per unit length for both the bridge deck and the equivalent plate were equal. In some solution the torsion rigidity was neglected for simplicity. Because the designer had only unrefined tools, i.e., slide rule or simple calculator at that times, the distribution coefficients were tabulated or charted. In spite of approximate assumptions of orthotropic plate theory the good engineering accuracy for wheel distribution usually was obtained for straight, simple supported bridges.

Later the load distribution methods were developed to characterize parameter or distribution coefficient methods [11, 12]. Actually the methods have been codified in the USA by AASHTO (1977) and Canada OHBDC (1983). More refined version of distribution coefficients is used in AASHTO LRFD Bridge Design Specification (1998). However the distribution coefficients in American codes are load-dependent and can be used only with traffic load models embodied in these codes. Using a refined approach in AASHTO LRFD Specification made the formulas for live load distribution very complex and some simplifications were required [9]. Live load distribution in bridges is still difficult to be precisely determined using simplistic or too crude formulas.

In the time of modern computers, old solutions for load distribution in bridge decks can be easily solved by a small computer program or using a spreadsheet calculator. As computers become widespread to designers, simple computer-based methods for wheel load distribution become more attractive than design tables or charts. The selection of numerical models in majority depends on availability of software, experience and required accuracy. For load distribution very simple grillage models are quite satisfactory and give good accuracy.

\section{Grillage Analysis}

Bridge analysis methods are changing with the development of computers [3, 10]. The refined computer methods such as the grillage analogy and the finite element method are now well established and have long technical literature. The numerical models for as built or conceptualized bridge systems involve limitations and assumptions as every numerical model is an approximation of a real system. Computer methods consider entire bridge structures as systems and allow to obtain a realistic distribution of loads.

In the paper, the grillage analogy is chosen to compute the wheel load distribution problem, as a method that simply model most common types of bridge decks. 2D models (plane grillage) are used but bridge decks may be also modeled as a 3D system. Each bridge type requires special grillage modelling technique, clear recommendations are given in the literature $[3,10]$. The main advantage of plane grillage 
analysis is that shear and moment values for girders are directly obtained and there is no need for integration of stresses. For every adopted grillage mesh its concordance and deformability should be checked.

For the wheel load distribution purposes even a coarse grillage mesh is sufficient, but idealization of a bridge deck should depend upon its structural behavior rather than on a set of rules. It is recommended that grillage simulates the bridge deck by having its longitudinal members coincident with centerlines of deck's beams. The same is for the transverse beams plus the slab or the slab-strips to model grillage transverse members. The spacing of transverse members should be sufficient to distribute the effects of concentrated wheel or axel loads. Parameters of the beams and transverse members are usually based on uncracked section and elastic behavior. The flexural and torsional properties of the members are calculated by simple well-known formulas $[2,3,10]$.

Different spacing of girders, individual parameters of beams, skew of the deck and even cracking of concrete can be taken into account in grillage idealizations. These parameters are rarely considered in design charts based on orthotropic plate analogy or similar simplified methods. The grillage analogy generally produces more accurate results and then presents a good alternative to other simplified bridge deck analysis methods. It is developed in many clear computer programs and data and results can be processed in a very short time. It makes the method economical and clear to the majority of engineers.

\section{Numerical Method}

Traffic loads on bridge decks are distributed according to the stiffness, geometry and boundary condition of the decks. In presented method, the grillage analysis is used for modeling of bridge decks. The example slab-girder bridge deck, its cross section, plan and equivalent grillage members are presented in
Fig. 1. In the grillage approach the bridge deck is idealized as an assembly of several longitudinal beams placed along the centerlines of bridge girders. The beams are given the flexural and torsional properties of the girders. The same is for transverse members. The grillage analysis is applied with the help of conventional computer programs so numerical mathematics is done by computers.

The bridge girders are loaded at critical section with a load $P$. The average deflection of the bridge system is $f_{0}$ (Fig. 1c). The sum of the girders deflections $f_{N}$ which is the total deflection of $N$ girders at a given cross section. But the bridge deck is not a one-dimensional beam. Due to the torsional stiffness of the bridge members the concentrated load $P$ applied to the bridge girders makes cross section deformations. The higher the torsional rigidity of bridge girders, the more uniform the girder deflections are. The nonuniformity of girder deflections indicates load distribution. The deflection of girder $i$ due to load $P$ on
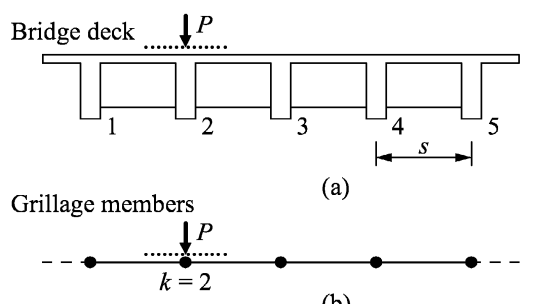

(b)

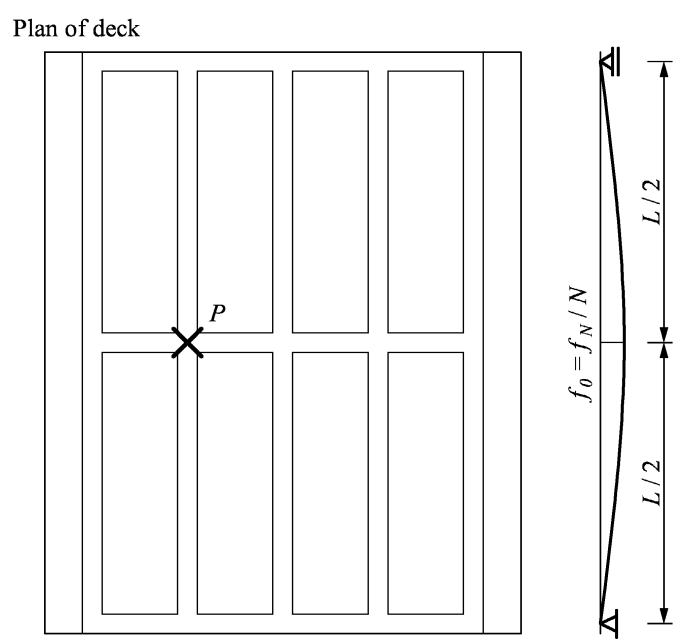

(c)

Fig. 1 Scheme of a slab-on-girder bridge deck, simply supported: cross section (a), its equivalent grillage members (b), plan and deflections (c). 
girder $k$ is defined as $f_{i k}$. The deflection lines of bridge cross section under the load at the three girders are presented in Fig. 2.

Then the average deflection $f_{0}$ at midspan of the bridge system is:

$$
f_{0}=\frac{1}{N} \sum_{i=1}^{N} f_{i k}=\frac{1}{N} f_{N}
$$

where: $N=$ number of girders; $f_{i k}=$ deflection of girder $i$ due to force at girder $k ; f_{N}=$ total deflection.

The ratio of two deflections, produced by load $P$ and by distributed load $p_{0}=P /$ width of deck is called the principal coefficient of transverse load distribution $K[1]$ :

$$
K_{i k}=\frac{f_{i k}}{f_{0}}
$$

The transverse load distribution coefficient $\kappa$ is described by the formula using Eqs. (1) and (2):

$$
\kappa_{i k}=\frac{K_{i k}}{N}=\frac{f_{i k}}{f_{N}}
$$

where: $\kappa_{i k}=$ distribution coefficient for girder $i$ at

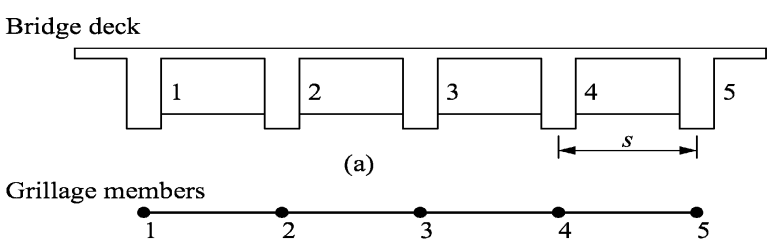

(b)

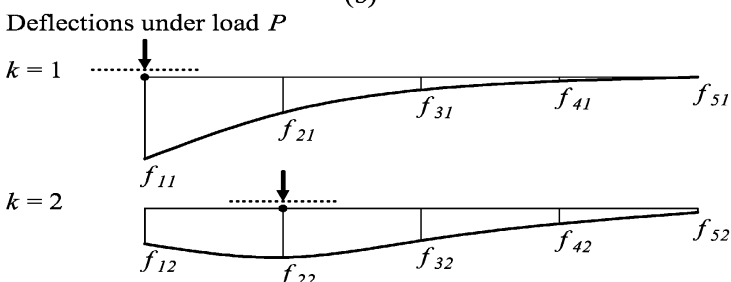

$k=3$

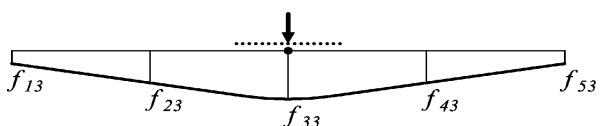

(c)

Influence line for load distribution

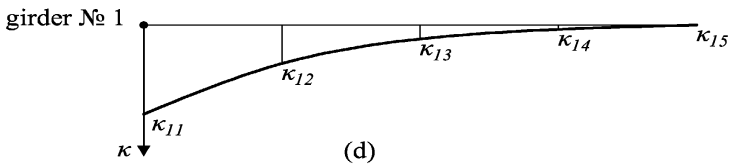

Fig. 2 Scheme of obtaining influence lines for live load distribution: cross section (a), equivalent grillage members (b), bridge girder deflections due to force at girder № 1, 2,3 (c), and live load distribution coefficients for external girder № 1 (d). point $k ; K_{i k}=$ principal coefficient of load distribution; $N=$ number of girders.

Deflections according to Maxwell's reciprocal theorem can be written as $f_{i k}=f_{k i}$. It states that the deflection produced at the girder $i$ due to a unit-load applied at the girder $k$ is equal to the deflection which a unit-load applied at girder $i$ would produce at girder $k$. It means that the deflection $f_{k i}$ can be used instead of the deflection $f_{i k}$ in Eq. (3):

$$
\kappa_{i k}=\frac{f_{k i}}{f_{N}}
$$

The graphical presentation of preparing the influence line of transverse load distribution for external girder (№ 1) is presented in Fig. 2. For a bridge with $N$ girders, the solution requires $N$ distribution coefficients for each girder computed according to the Eq. (3) or (3a). All these coefficients are dimensionless and can be used in the same way as an usual influence line. For calculating these values only one computer run is required and for any grillage computer program it takes a part of second.

Using grillage approach for bridge decks analysis requires some experience and basic knowledge for modelling behavior of bridge systems. For checking the results the Maxwell's theorem can be applied and the distribution coefficients $\kappa_{i k}$ for girder $k$ must be obeyed to the equation:

$$
\sum_{k=1}^{N} \kappa_{i k}=1.000
$$

where: $\kappa_{i k}=$ distribution coefficient for girder $i$ at point $k ; N=$ number of girders.

The formula means that the sum of the coefficient for all girders is 1.000 and this confirms that no errors have been made.

Using the load $P$ for calculation of distribution coefficients $\kappa$ is a safe approach as for the axel or vehicle load the values of $\kappa$ are smaller.

The presented procedure may also be adopted for calculation of distribution coefficients $\kappa$ using bending moments or stresses instead of deflections. 


\section{Examples}

The numerical method for distribution of loads effects in transverse direction can be adopted for analysis of as built or conceptualized bridge decks. The influence lines $\kappa$ and required position of traffic loads according to Polish code are presented for two reinforced concrete bridge decks which were verified by the author. The traffic model consists of uniformly distributed load $q$ (UDL) plus a four-axle special vehicle. The graph of the $\kappa$-line enables to find the required position of loads at glance. The both bridges were constructed before the Second World War and the structures are out of modern rules. Now they are situated at the county roads. They are chosen for the examples because they are not typical for today practice and are difficult to analyze by traditional load distribution methods. The girders have low torsional rigidity and that makes the decks vulnerable to wheel loads. For decks with stiffer girders the deflections and the load distributions are not so high and are more uniform. For sufficient distribution of wheel loads the spacing of the grillage transverse elements is taken rather small.

\subsection{Multi-beam Skew Bridge}

The simple supported bridge span is $17.1 \mathrm{~m}$ (Fig. 3). The deck has got seven main girders and two sidewalk girders. The skew of the span is app. $77^{\circ}$.

The bridge was assessed for repair and strengthening. The adopted grillage mesh and the load distribution graph for the external main girder is presented in Fig. 3. The comparison with a simplistic method (eccentric compression) gives pour results (Fig. 3b). The design load is positioned for maximum load effects for the external girders.

\subsection{Two Span Bridge}

The continuous bridge has two right span of 13.12 m (Fig. 4). The deck has got four reinforced concrete girders. There was limited reinforcement in external girders as the bridge had been design for one-lane traffic and no transverse live load distribution had been used in the design. The bridge was assessed to check its load capacity and find additional strength for heavier agriculture vehicles. The grillage distribution

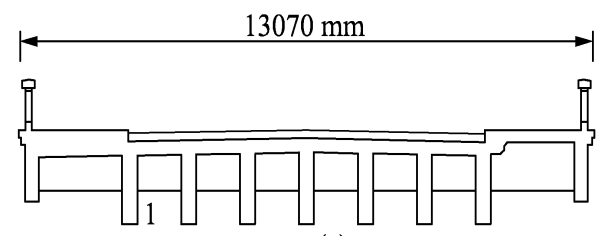

(a)

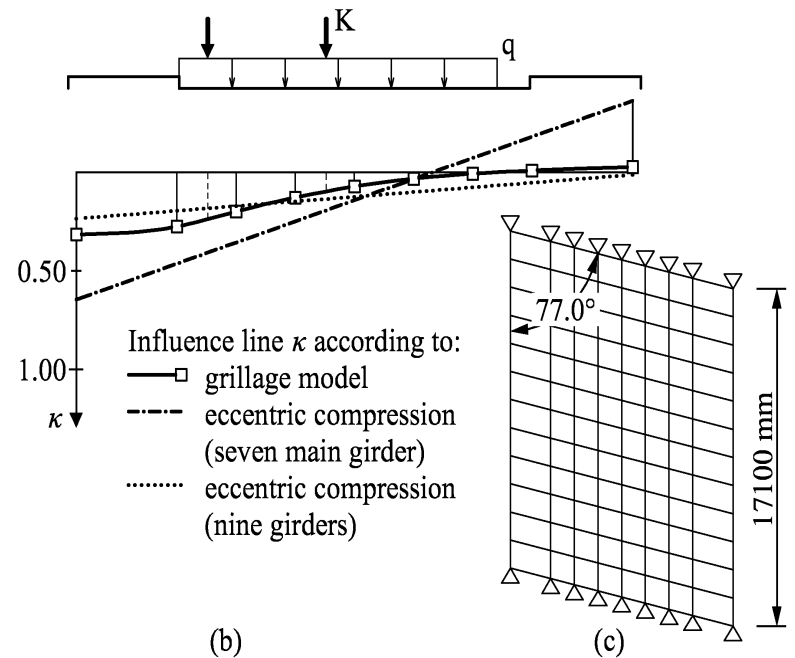

Fig. 3 Cross section (a), live load distribution for external main girder № 1 (b), and grillage mash (c) of multi-girder concrete bridge.

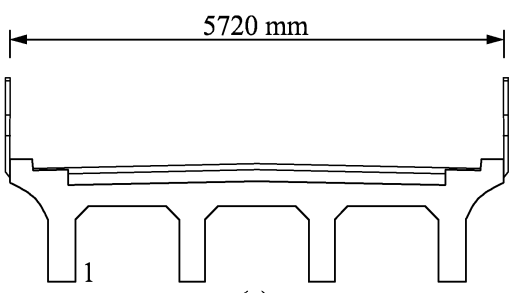

(a)
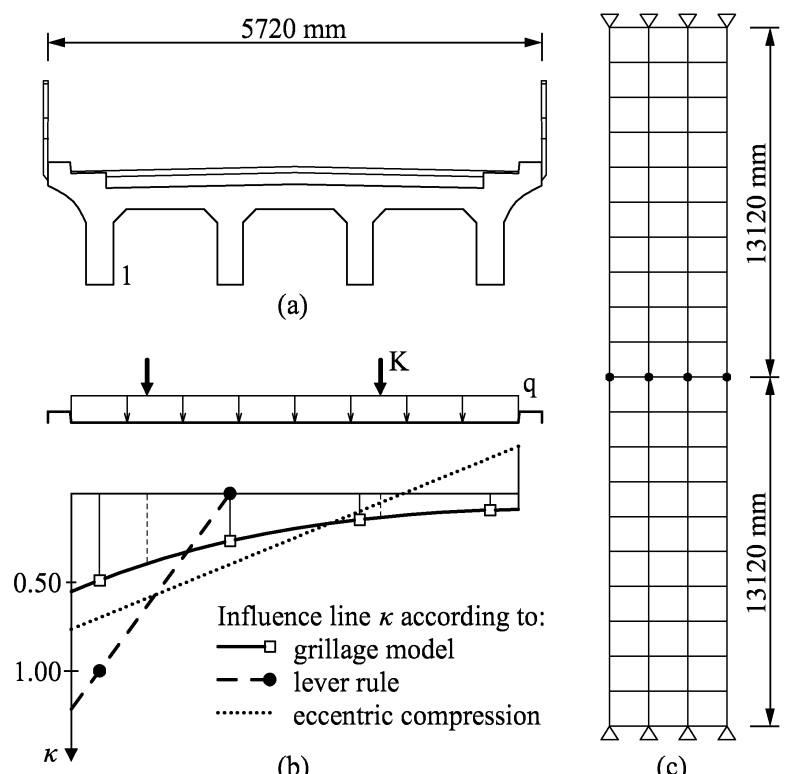

(c)

Fig. 4 Cross section (a), load distribution for external girder № 1 (b), and grillage mesh (c) of four-girder concrete bridge. 
gives a little smaller value than simplified procedures and it is the required reserve of load capacity.

In design and assessment of road bridges traffic load actions are necessary to consider in a realistic way. Transverse distribution of wheel loads onto bridge girders must be done correctly and precisely, but also possibly in a simple way. The presented examples allowed assessing the resistance of existing road bridges in more accurate manner and some "hidden" reserves of strength were asserted.

\section{Conclusions}

In the paper the general numerical method of computing distribution of wheel loads is presented. By using influence lines for live load distribution there is no specific load required and the method can implement any national or international code traffic load model. The grillage analogy is adopted for computing load distribution coefficients as a numerical method well-established, accurate and comprehensive to engineers. However other numerical methods can be introduced as well.

The presented numerical method for distribution of wheel load effects in girder bridges allows for more rigorous assessment than using the lever rule or simplified distribution factors [6]. Grillage models of bridge deck are very comprehensive and not time consuming. The results of computed and measured in-situ deflections are very similar. The uncertainty and approximation in live load analysis of bridge decks may be avoided by developing individual numerical models. The calculated distribution coefficients are very similar in the form to the traditional simplified distribution factors which have been used in bridge design for many years.

\section{References}

[1] Bareš, R., and Massonnet, Ch. 1968. Analysis of Beam Grids and Orthotropic Plates by the Guyon-Massonnet-Bareš Method. Crosby Lockwood \& Son Ltd, SNTL, London-Prague.

[2] Barker, R. M., and Puckett, J. A. 2007. Design of Highway Bridges. An LRFD Approach. 2nd ed. John Wiley \& Sons, Hoboken - New Jersey.

[3] Hambly, E. C. 1991. Bridge Deck Behaviour. 2nd ed. Taylor \& Francis, London - New York.

[4] Hołowaty, J. 1993. "Numerical Modelling of Bridge Decks in Practical Examples." Proceedings of the IX Polish Conference on Computer Methods in Mechanics, 331-6.

[5] Hołowaty, J. 2010. "Numerical Method for Live Load Distribution in Road Bridges." Proceedings of the Fourth International Conference on Advances and Trends in Structural Engineering, Mechanics and Computation, 425-8.

[6] Hołowaty, J. 2012. "Live Load Distribution for Assessment of Highway Bridges in American and European Codes." Structural Engineering International, SEI 22 (4): 574-8.

[7] Hołowaty, J. 2013. "Assessment of Numerical Models for Live Load Distribution in a Road Slab Bridge.” Journal of Computer Technology and Application 4 (11): 591-8.

[8] Hołowaty, J. 2014. "Live Load Distribution in a Composite Road Bridge-Numerical Models and Load Tests." Proceedings of the 7th European Conference on Steel and Composite Structures, Eurosteel 2014, 719-20.

[9] NCHRP. 2007. Simplified Live Load Distribution-Factor Equations. TRB Report 592, Washington.

[10] O'Brien, E. J., and Keogh, D. L. 1999. Bridge Deck Analysis. E\&FN Spon, London.

[11] Ryall, M. J. 2008. Loads and Load Distribution, ICE Manual of Bridge Engineering. 2nd ed., edited by Parke, G., and Hewson, N. Thomas Telford, London, 23-48.

[12] Bakht, B., and Jaeger, L. G. 1985. Bridge Analysis Simplified. McGraw-Hill, New York. 